\title{
Hyperbranched polymer surfactant: synthesis, characterization and surface tension activity
}

\author{
Longfang Ren ${ }^{1,2^{*}}$, Zheng Tang ${ }^{1,2}$, Taotao Qiang ${ }^{1,2}$ and Guoguo Zhang ${ }^{1,2}$
}

\begin{abstract}
A series of hyperbranched polymer surfactants (HBP-C8, HBP-C12 and HBP-C16) were synthesized by the reaction between hydroxyl-terminated hyperbranched polymers (HBP) and fatty acyl chloride. The structure of obtained hyperbranched polymer surfactant was characterized by FTIR, NMR and GPC. The results showed that the products have amphiphilic structure. The thermal property of the hyperbranched polymer surfactant investigated by DSC and TGA was strongly influenced by the length of end alkyl chain. Surface activity of hyperbranched polymer surfactant was analyzed by surface tension method and UV spectrophotometry, respectively. The results showed that hyperbranched polymer surfactant took on better surface activity, which can effectively reduce the surface tension of the water. The hyperbranched polymer surfactant has a lower critical micelle concentration (CMC) and displays single molecular micellar properties, which can package small hydrophilic molecules in relatively low concentration.
\end{abstract}

Keywords: Fatty acid chloride, Hyperbranched polymer, Surface tension, CMC

\section{Introduction}

Hyperbranched polymers are three-dimensional structures of highly branched with rich in active end groups, and have the characteristics of high solubility and strong shear resistance, and so on [1-4]. There can be modified by end groups to obtain the desired properties. The modification methods of hyperbranched polymers are generally divided into three types, namely grafting method $[5,6]$, inlaying method [7] and blending method [8]. Due to the special properties of hyperbranched polymers, so they have broad application prospects in medical, coating, environmental protection and other fields [9-11].

Among these a new type of hyperbranched polymer surfactants can be obtained by modification reaction. Hyperbranched polymer surfactants can be divided into two types, linear-dendritic and core-shell structures [12].

\footnotetext{
* Correspondence: renlf1010@163.com

'College of Bioresources and Materials Engineering, Shaanxi University of Science \& Technology, Xi'an 710021, China

${ }^{2}$ National Demonstration Center for Experimental Light Chemistry

Engineering Education (Shaanxi University of Science \& Technology), Xi'an 710021, China
}

There is a linear long chain at one end and a hyperhydrophilic or lipophilic groups [13]. Core-shell structured hyperbranched polymer surfactants generally use the polymer as the core, and linear long chain grafted through the end groups, based on this, the structure is divergent to the surrounding, and not

Up until now, the research of hyperbranched polymer surfactants has mainly focused on self-assembly $[6,18$, 19]. Through self-assembly process, various assembly found that this hyperbranched block polyether can take branched poly (amide-ester) surfactants. Studies have shown that such surfactants can self-assemble into 
micelles in water, which with good stability and emulsifying ability [15]. However, the surface activity of hyperbranched polymer surfactants is greatly different from traditional small molecule surfactants due to its unique molecular structure and multi-terminal hydrophilic/ hydrophobic structure. The research about the surface activity of hyperbranched polymer surfactant has seldom studied.

In this paper, a kind of hyperbranched polymer surfactant was prepared by using fatty acyl chloride and hydroxyl terminated hyperbranched polymer in which there are large number of hydrophilic hydroxyl and hydrophobic alkyl chain, and then its surface activity is studied by surface tension method and UV spectrophotometry. Such a new type of surfactant with multiterminal hydrophilic/hydrophobic structure demonstrates better surface activity, and has a lower critical micelle concentration and display single molecular micellar properties, which can package hydrophilic small molecule in relatively low concentration.

\section{Experimental}

\subsection{Materials}

Octylic acid (A.R.), lauric acid (A.R.), palmitic acid (A.R.), thionyl chloride (A.R.) were purchased from Xiya reagent Company and used directly. Pyridine (A.R.), chloroform (A.R.), iodine (A.R.), potassium iodide (A.R.) were obtained from Tianjin Fuchen Chemical Company and used directly.

\subsection{Synthesis of hyperbranched polymer surfactant}

Octylic acid $(0.01 \mathrm{~mol}, 1.442 \mathrm{~g})$, lauric acid $(0.01 \mathrm{~mol}$, $2.003 \mathrm{~g})$ and palmitic acid $(0.01 \mathrm{~mol}, 2.564 \mathrm{~g})$ were added into a three-necked flask, respectively. Thionyl chloride $(0.015 \mathrm{~mol}, 1.784 \mathrm{~g})$ was added dropwise with stirring, and then the system was allowed to react for $2 \mathrm{~h}$. The solution was transferred to a rotary evaporator, and unreacted thionyl chloride was removed under reduced pressure. Specific synthetic process was shown in Fig. 1.

The hydroxyl terminated hyperbranched polymers (HBP) were synthesized by polycondensation reaction according to the literature [24]. And the hydroxyl value of HBP was measured for $2.45 \mathrm{mmol} \cdot \mathrm{g}^{-1}$. Different types of fatty acyl chloride were used to synthesize a series of hyperbranched polymer surfactants with different carbon chains (HBP-C). The specific synthetic process of octanoyl chloride modified hyperbranched polymers was as follows. Under a nitrogen atmosphere, HBP $(10.0 \mathrm{~g}$, containing $0.0245 \mathrm{~mol}$ hydroxyl) was added in a reaction

$$
\mathrm{CH}_{3}\left(\mathrm{CH}_{2}\right)_{x} \mathrm{COOH}+\mathrm{SOCl}_{2} \stackrel{\Delta}{\longrightarrow} \mathrm{CH}_{3}\left(\mathrm{CH}_{2}\right)_{x} \mathrm{COCl}
$$

Fig. 1 Synthesis of fatty acyl chloride flask, and then certain amount of pyridine (slightly submerged HBP) was added to dissolve HBP. Finally, the flask was placed in an ice-water bath. The octanoyl chloride was added dropwise into above reaction system with vigorous stirring. The reaction was carried out under different temperature for $24 \mathrm{~h}$. The solution was transferred to a rotary evaporator to remove pyridine under reduced pressure, and then a pale yellow crude product was obtained. The crude product was dissolved in chloroform and washed by deionized water for three times to remove pyridine hydrochloride. The organic phase was collected and the solvent was removed on a rotary evaporator. The resultant product was dried in vacuum at $40^{\circ} \mathrm{C}$ for 2 days to obtain the pale yellow solid powder (HBP-C8). Taking HBP-C8 as example, the specific synthetic reaction formula was shown in Fig. 2. HBP-C12 and HBP-C16 were obtained by the same method.

\subsection{Testing and characterization 2.3.1 Grafting rate}

The hydroxyl value of HBP and HBP-C were measured according to the literature [25], respectively. The grafting rate of products can be calculated by formula (1).

$$
\text { Grafting rate }(\times 100 \%)=\left(\mathrm{A}_{0}-\mathrm{A}_{1}\right) / \mathrm{A}_{0}
$$

Where $\mathrm{A}_{0}$ and $\mathrm{A}_{1}$ were the hydroxyl value of $\mathrm{HBP}$ and HBP-C, respectively.

FTIR spectrum was performed on a VECTOR-22 FTIR spectrometer (BRUKER Co, Germany). The measurement was done using $\mathrm{KBr}$ pellets, and the scanning range was $4000 \sim 500 \mathrm{~cm}^{-1}$.

${ }^{1} \mathrm{H}$-NMR and ${ }^{13} \mathrm{C}$-NMR spectra were recorded at $25^{\circ} \mathrm{C}$ on a Varian INOVA $500 \mathrm{MHz}$ spectrometer (BRUKER Co, Germany). $\mathrm{CDCl}_{3}$ was used as the solvent.

Differential scanning calorimetry (DSC) measurements were carried out on a DSC-204 (NETZSCH Co, Germany) in the temperature range $20^{\circ} \mathrm{C} \sim 120^{\circ} \mathrm{C}$ at a heating rate of $10^{\circ} \mathrm{C} \cdot \mathrm{min}^{-1}$ and nitrogen flow rates of $40 \mathrm{~mL} \cdot \mathrm{min}^{-1}$.

Thermogravimetric analysis (TGA) was carried out on TGA Q500 (TA Co, American) in the temperature range of $30^{\circ} \mathrm{C} \sim 600^{\circ} \mathrm{C}$ at a heating rate of $10^{\circ} \mathrm{C} \cdot \mathrm{min}^{-1}$ and nitrogen flow rates of $40 \mathrm{~mL} \cdot \mathrm{min}^{-1}$.

\subsection{Surface tension activity of HBP-C}

The HBP-C was dissolved in water to obtained polymer aqueous solution with different mass concentration. The surface tension activity of polymer solution was performed on QBZY-1 automatic surface/interfacial tension meter (Shanghai Fangrui Instrument Co. Ltd.). 

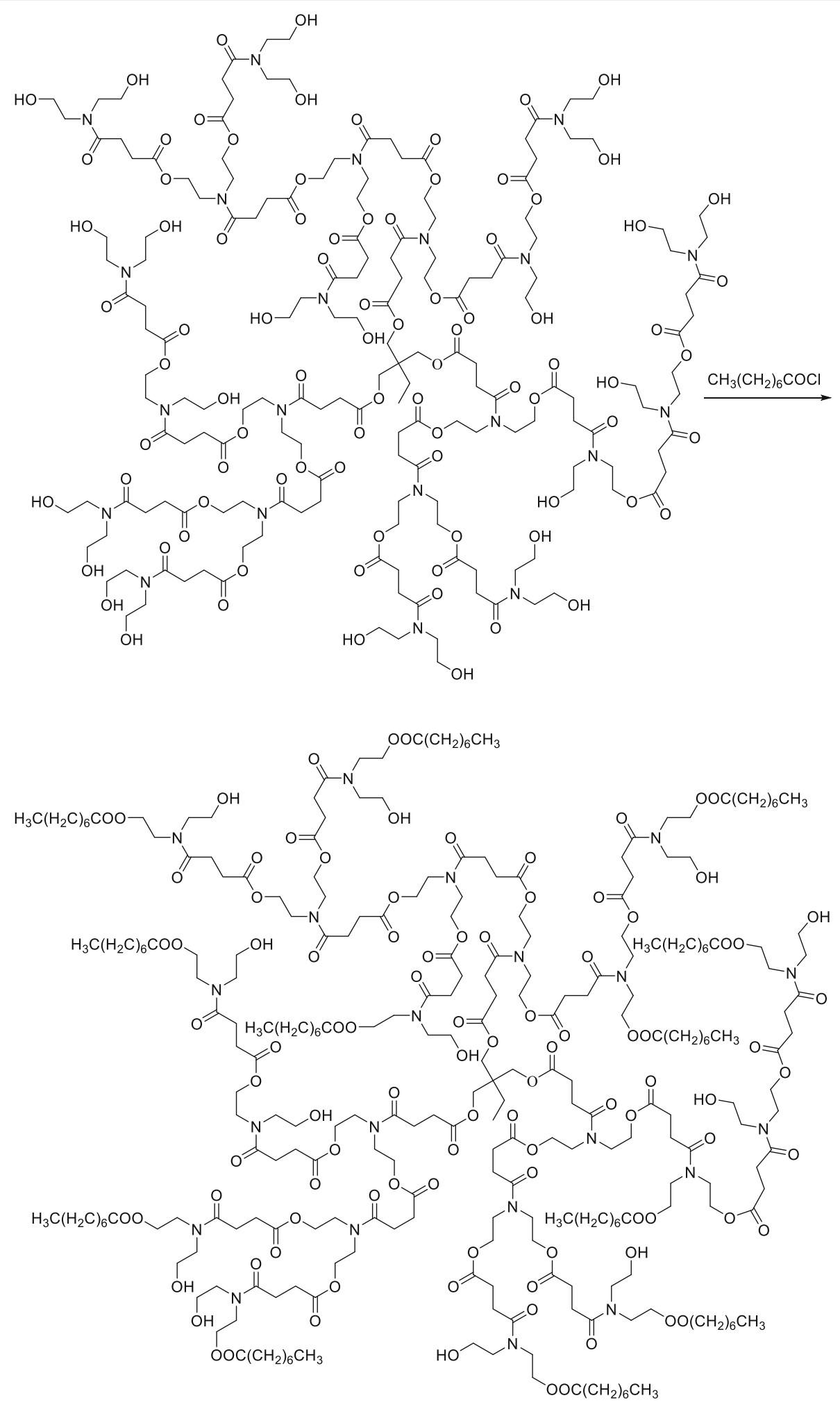

Fig. 2 Synthesis of HBP-C8

Fig. 2 Synthesis of HBP-C8 


\subsection{Critical micelle concentration (CMC) of HBP-C}

CMC of HBP-C was determined by UV spectrophotometry. The iodine aqueous solution $\left(\mathrm{I}_{2}, 10 \mathrm{mmol} \cdot \mathrm{L}^{-1}\right)$ and potassium iodide aqueous solution $\left(\mathrm{I}^{-}, 10 \mathrm{mmol} \cdot \mathrm{L}^{-1}\right)$ was mixed under stirring, and then it was tested by UVvis spectra. The results show that mixed solution has obvious absorption peak at $288 \mathrm{~nm}$ and $350 \mathrm{~nm}$, the $\mathrm{I}_{3}{ }^{-}$ aqueous solution $\left(5 \mathrm{mmol} \cdot \mathrm{L}^{-1}\right)$ has been completely obtained.

$\mathrm{I}_{3}{ }^{-}$aqueous solution $(1 \mathrm{~mL})$ was mixed with HBP-C solution $(24 \mathrm{~mL})$. The solution was shaken for $10 \mathrm{~min}$ and equilibrated at room temperature in a dark chamber for $30 \mathrm{~min}$. The mixed solution was measured by UV-vis spectra (Shimadzu Corporation, Japan) and the absorbance of the solution was obtained.

\section{Results and discussion}

\subsection{Characterization of HBP-C}

The FTIR spectra of HBP-C were shown in Fig. 3. As it can be seen from Fig. 3, The FTIR spectra of HBP-C8, HBP-C12 and HBP-C16 have similar absorption peaks. The characteristic peaks of HBP-C took on delicate difference with HBP. The absorption peak at $3382.53 \mathrm{~cm}^{-1}$ was the stretching vibration of $-\mathrm{OH}$ and at $2950.55 \mathrm{~cm}^{-1}$ was the stretching vibration peak of $-\mathrm{CH}_{2}-$ and $-\mathrm{CH}_{3}$. Compared with HBP, the absorption peaks of methyl and methylene in HBP-C were enhanced, which showed that the long carbon chains were introduced into the structure of HBP. The absorption peak at $1792.83 \mathrm{~cm}^{-1}$ and $1625.70 \mathrm{~cm}^{-1}$ were the stretching vibration peak of $\mathrm{COO}-$ and $\mathrm{CON}$ - in HBP-C which became stronger comparing with that of HBP.
The ${ }^{1} \mathrm{H}-\mathrm{NMR}$ spectra of HBP-C were shown in Fig. 4. As shown in Fig. 4, the signal "a" around 0.76 0.80 ppm was assigned to methyl protons in alkyl chain of HBP-OOC $\left(\mathrm{CH}_{2}\right)_{\mathrm{x}} \mathrm{CH}_{3}$, while the signal "b" around 1.24 1.26 ppm was attributed to methylene protons which linked with $-\mathrm{CH}_{3}$ in alkyl chains of $\mathrm{HBP}-\mathrm{OOCCH}_{2} \mathrm{CH}_{2}\left(\mathrm{CH}_{2}\right)_{x} \mathrm{CH}_{3}$. There were a large number of methylene-linked resulting the absorption peak was wide peak. The signal "c" around $1.7 \mathrm{ppm}$ was assigned to methylene protons of alkyl chains of $\mathrm{HBP}-\mathrm{OOCCH}_{2} \mathrm{CH}_{2} \mathrm{R}$, while the signal " $\mathrm{d}$ " around $2.0 \mathrm{ppm}$ was assigned to methylene protons in alkyl chains of $\mathrm{HBP}-\mathrm{OOCCH}_{2} \mathrm{R}$ which linked with -COO. The absorption peak around $5.00 \mathrm{ppm}$ belonged to the methylene protons of alkyl chains which linked with $-\mathrm{OH}$. The signal "e" around 2.56 4.17 ppm represented the protons in HBP. Due to $\mathrm{CDCl}_{3}$ was used as solvent, the absorption peak of hydroxyl and amphiphilic core were not obvious. The results showed that the characteristic absorption peak of alkyl chain was presented in the structure of HBP-C.

The ${ }^{13} \mathrm{C}-\mathrm{NMR}$ spectra of HBP-C (HBP-C8, HBP-C12 and HBP-C16) were shown in Fig. 5. Comparing the ${ }^{13} \mathrm{C}$-NMR spectra of HBP-C, the absorption peaks were nearly the same, only the characteristic absorption peaks of alkyl chain presented obvious difference. As $\mathrm{CDCl}_{3}$ was used as solvent, the absorption peak of hydrophilic core was not obvious, but the signal " $h$ " around $45.0 \sim 65.0 \mathrm{ppm}$ was the weak absorption peak of hydrophilic core. In Fig. 5a, there were seven kinds of absorption peak at $14.07 \sim 34.21 \mathrm{ppm}$ which corresponded to seven kinds of methyl and methylene in octyl. In Fig. 5b, there were eleven kinds of absorption peak at

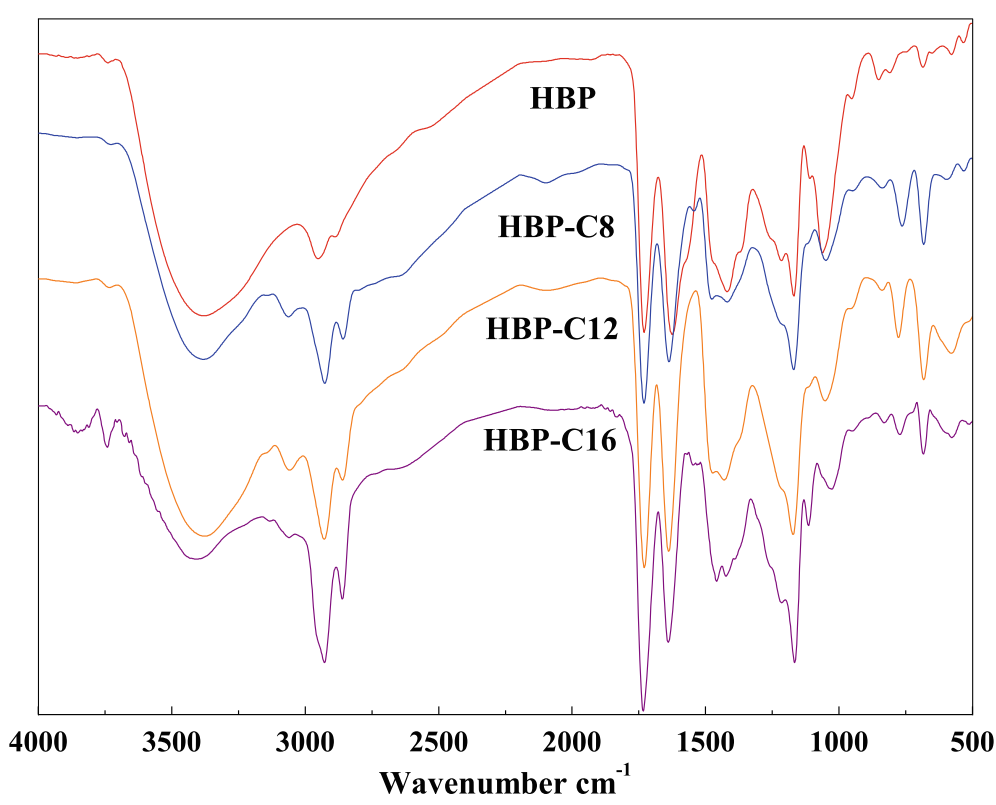

Fig. 3 FTIR spectra of HBP and HBP-C 


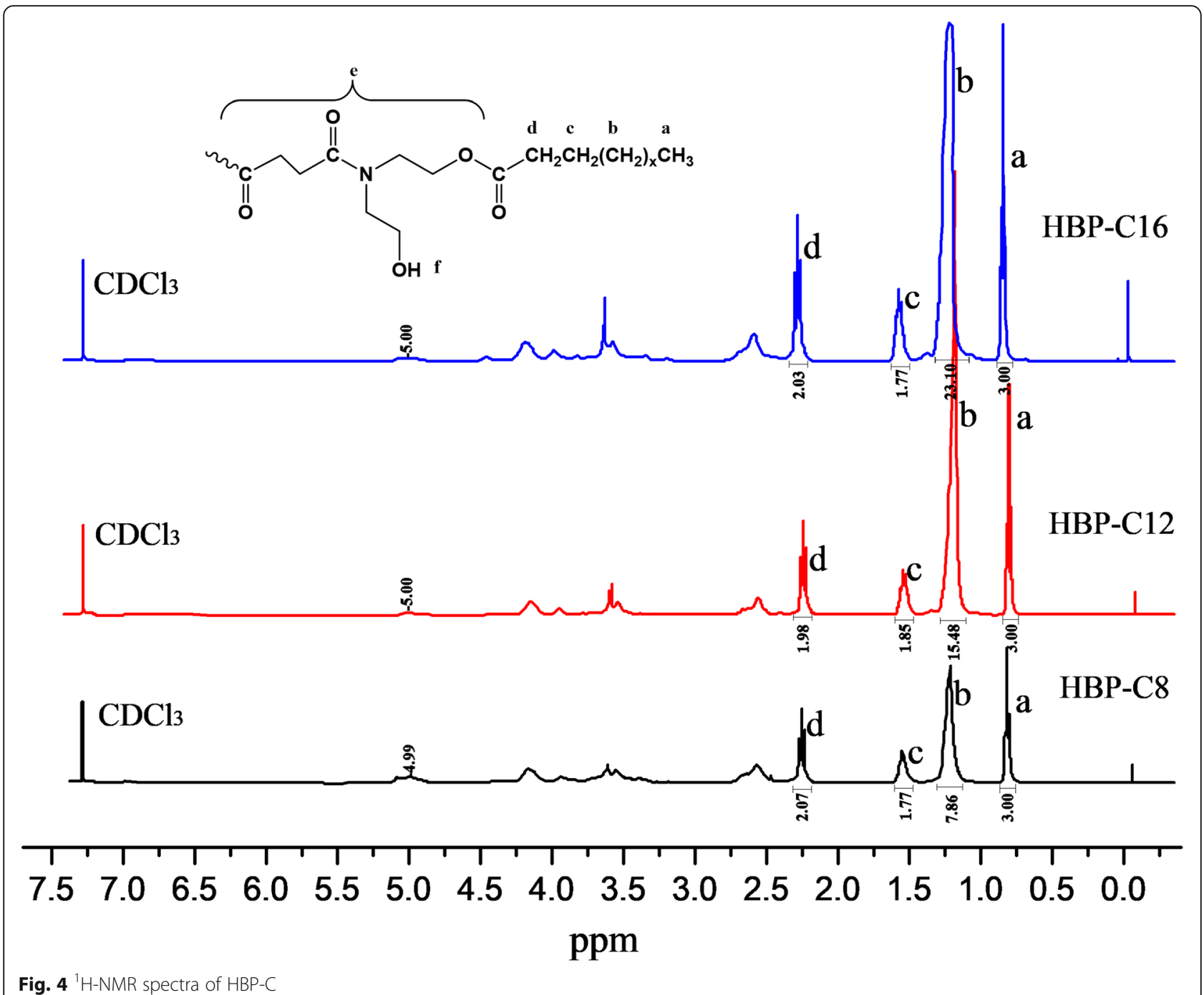

$14.07 \sim 34.21 \mathrm{ppm}$ corresponding to methyl and methylene in lauryl. In Fig. 5c, there were 15 kinds of absorption peak at $14.07 \sim 34.21 \mathrm{ppm}$ which belonged to different kinds of methyl and methylene in palmityl. In Fig. 5b and c, Because of many connected methylene, the peak at around $29.5 \mathrm{ppm}$ appeared accumulation peak. The results showed that HBP-C has the characteristic absorption peak of alkyl chains, so they were successfully synthesized by the modification reaction.

\subsection{Optimization of HBP-C}

\subsubsection{Reaction temperature}

According to above synthesis method, HBP-C8 was synthesized under different temperatures and the effect of temperature on the grafting rate was discussed. The results were shown in Fig. S1.

According to the acylation reaction mechanism, the first step of acylation reaction is an exothermic reaction, and low temperature is conducive to the reaction, but if the temperature is too low, it will cause the crystallization of the amide salt. The second step of acylation reaction is a slightly endothermic reaction, so higher temperature is beneficial to the reaction. But it will increase the side reaction and cause the polymerization of the amide salt when the temperature is too high. However, in this manuscript the hydroxyls are located on the structure of hyperbranched polymers, as well as the activity of the aliphatic acid chloride may be gradually weakened with the increase of the alkyl carbon chain. In addition, due to the steric effect, the larger the volume of the main chain connected to the hydroxyl group, it is less conducive for the acylation reaction. Therefore, the acylation reaction using fatty acid chlorides with hydroxyl-terminated hyperbranched polymers with different carbon chain lengths may be different from general acylation reaction. So the effect of temperature is studied. The results showed that the grafting rate at room temperature and ice-water bath 


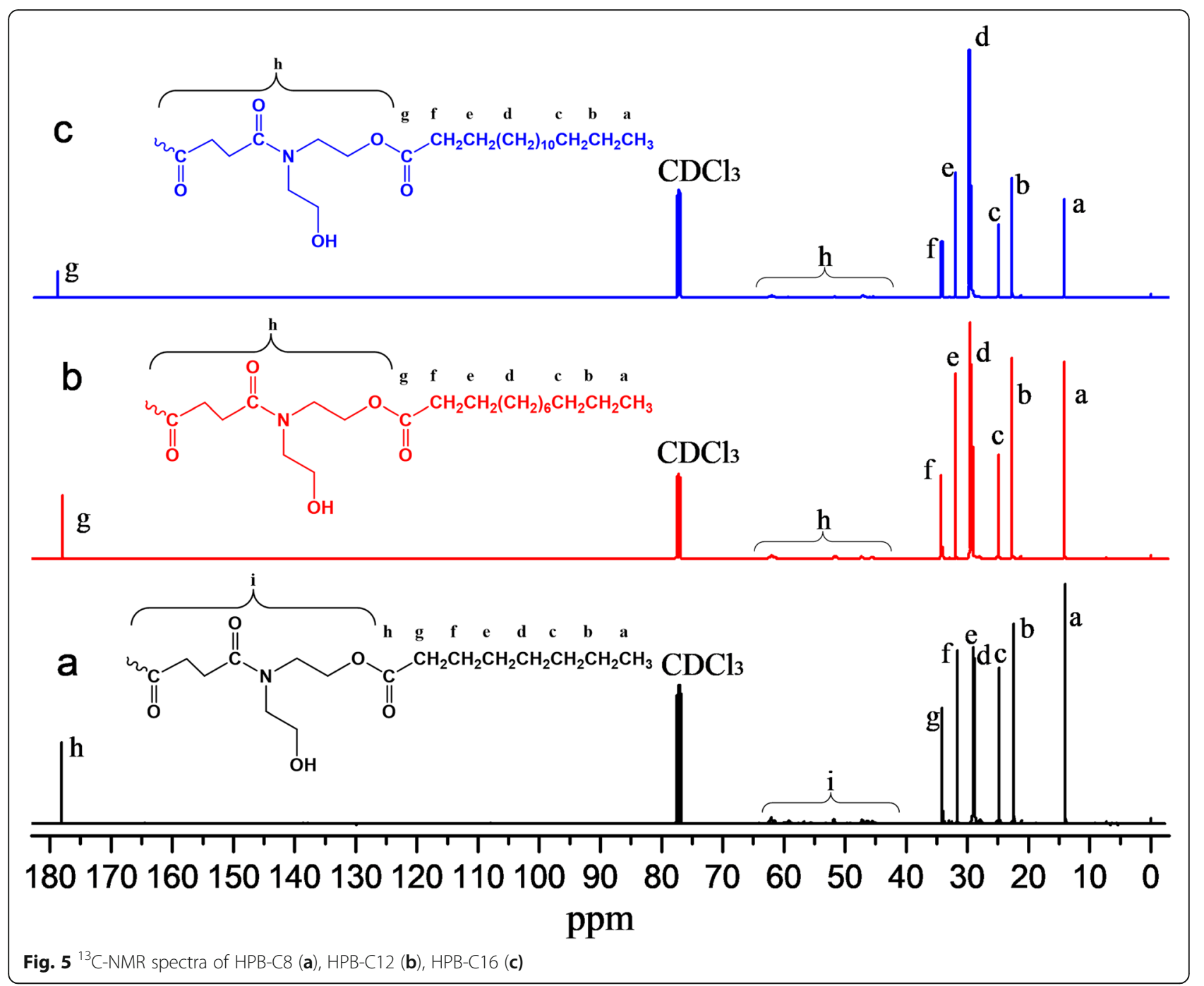

has very small fluctuation. The main chain of hyperbranched polymer nearly has no effect on the reaction of hydroxyl and aliphatic acid chloride.

\subsubsection{Solvent dosage}

According to above synthesis method, HBP-C8 was synthesized under different dosages of pyridine $(10,20,40$ $\mathrm{mL}$ ) and the effect of solvent dosage on the grafting rate was discussed. The results were shown in Fig. S2.

The influence of solvent dosage on grafting rate was shown in Fig. S2. In this acylation reaction, pyridine is used as the solvent. Pyridine has a catalytic effect and it can make the terminal chain of hyperbranched polymer take on a relatively stretched state, so that the terminal hydroxyl group can be better exposed to the periphery of the molecule and react with the acid chloride. In addition, pyridine also can replace the alkali solution to neutralize $\mathrm{HCl}$ generated during the acylation reaction, which can promote the proceeding of the acylation reaction and achieve greater conversion rate. If the amount of pyridine is too few, it will not create good environment for the acylation reaction. As shown in Fig. 4, when the amount of solvent is $10 \mathrm{~mL}$, the grafting ratio is $43.1 \%$, and when the amount of solvent is increased to $20 \mathrm{~mL}$, the grafting ratio was $48.6 \%$. Therefore, the effect of the amount of solvent is not obvious. Taking the purification of product into account, the dosage of pyridine was $20 \mathrm{~mL}$.

\subsection{Grafting rate of HBP-C}

The grafting rate of HBP-C was determined and the results were listed in Table 1.

The grafting rate of HBP-C was shown in Table 1. It can be seen from Table 1, the measured grafting rate of HBP-C was slightly lower than that of theoretical value. The end of HBP molecular chain can fold inwards, which leads to the terminal hydroxyl group is present 
Table 1 The grafting rate of HBP-C

\begin{tabular}{lll}
\hline Product & Theoretical grafting rate $\%$ & Measured grafting rate $\%$ \\
\hline HBP-C8 & 50 & 48.6 \\
HBP-C12 & 50 & 46.2 \\
HBP-C16 & 50 & 45.7 \\
\hline
\end{tabular}

inside of the molecules, as a result, it is hard to perform for acylation reaction. In addition, the terminal hydroxyl groups is wrapped with the introduction of alkyl chains, so the actual grafting rate is lower than that of theoretical value.

The molecular weight of HBP-C was characterized by GPC and the results were shown in Table 2. As seen from the results, the experimentally measured molecular weights of HBP-C were lower than the theoretical values obtained from the idealized models. With the increase of alkyl chain, the molecular weight of HBP-C gradually increased, as well as the molecular weight distribution gradually increased and became irregular. Because HBP has unique molecular structure, the molecular weight and the molecular weight distribution of HBP-C was not in conformity with the classic polycondensation reaction rule. On the other hand, because PS standard-based GPC measurements underestimate the molecular weight of HBP, a discussion on those differences on a quantitative level is meaningful.

\subsection{Thermal properties of HBP-C}

The glass transition temperature $\left(\mathrm{T}_{\mathrm{g}}\right)$ of HBP is different from that of traditional linear polymers. HBP has a large number of terminal functional groups, so its glass transition temperature is affected by the terminal functional groups. The temperature cannot reflect the flexibility and free volume of the movement unit, but reflect the interaction of the terminal functional groups [26].

The $\mathrm{T}_{\mathrm{g}}$ of HBP-C was determined by DSC and the results were shown in Table 2. As seen from the results, $\mathrm{T}_{\mathrm{g}}$ of HBP-C with longer alkyl chain was obviously higher than that of with short alkyl chain. The reason may be it is easy to produce mutual entanglement for long alkyl chain and cause the folding of the chains. As a result, the free volume of HBP-C is reduced, and the degree of restriction to the movement of the molecular chain is also increased, which results in an increase of $\mathrm{Tg}$. Secondly, the increase in chain length will lead to an increase in the molecular weight of the polymer, which will eventually increase $\mathrm{Tg}$.

The TGA thermogram of HBP-C was shown in Fig. 6. As seen from the Figure, the length of terminal alkyl chain has major influence on thermal stability of HBP-C. The thermal stability of HBP-C8 was significantly lower than that of HBP-C12 and HBP-C16. HBP-C8 has 5\% weight lost when the temperature was just $100^{\circ} \mathrm{C}$, while HBP-C12 and HBP-C16 have 5\% weight lost when the temperature was nearly $160^{\circ} \mathrm{C}$. Moreover, three kinds of products were completely decomposed when the temperature was higher than $400^{\circ} \mathrm{C}$. The end alkyl chain of HBP-C8 was the shortest, it was difficult to produce mutual entanglement, so HBP-C8 began to decompose in lower temperature. HBP-C12 and HBP-C16 had longer end alkyl chains, so the interaction between end alkyl chains leaded to higher thermal decomposition temperature. But three kinds of modified product belong to aliphatic polymers, so products were completely decomposed at higher temperature.

\subsection{Surface tension of HBP-C}

Surface tension of HBP-C (HBP-C8, HBP-C12 and HBPC16) were shown in Fig. 7. As shown in Figure, three kinds of modified product made the surface tension of the water obviously decrease. This is because there are many hydrophilic hydroxyls which can stretch into water and hydrophobic alkyl chains which penetrate into air on the special amphiphilic structure of HBP-C. A single surfactant molecules layer was formed on the surface of water by the balance of hydrophilic hydroxyl and hydrophobic alkyl chain, which can effectively reduce the surface tension of water. Because of HBP-C has a special molecular structure, its forming on water surface was different from traditional small molecule surfactant [27]. The spherical hydrophilic core occupied more space and multiterminal hydrophobic long chain can be free to air, so HBP-C can effectively reduce the surface tension of the water in relatively low concentrations. From above three figures, the surface tension gradually reduced when the concentration of HBP-C in water increased. It can be seen that with the increase of the grafted carbon chain length, the $\mathrm{CMC}$ of the modified product decreases. The possible reason is that the longer carbon chain increases the amount of $-\mathrm{CH}_{2}$ on the polymer surface, which makes the hydrophobicity be enhanced. It can better reduce the surface tension of water, so that

Table 2 GPC results of HBP-C

\begin{tabular}{|c|c|c|c|c|c|}
\hline Polymer & Theoretical $M_{n}(\mathrm{~g} / \mathrm{mol})$ & $M_{n}(\mathrm{~g} / \mathrm{mol})$ & $M_{w}(g / m o l)$ & $M_{w} / M_{n}$ & $\mathrm{~T}_{\mathrm{g}} /{ }^{\circ} \mathrm{C}$ \\
\hline HBP-C8 & 4702.46 & 3503.98 & 5674.96 & 1.62 & 46.9 \\
\hline HBP-C12 & 4983.06 & 3772.67 & 7584.32 & 2.01 & 48.2 \\
\hline HBP-C16 & 5263.36 & 4126.91 & $11,925.38$ & 2.89 & 51.4 \\
\hline
\end{tabular}




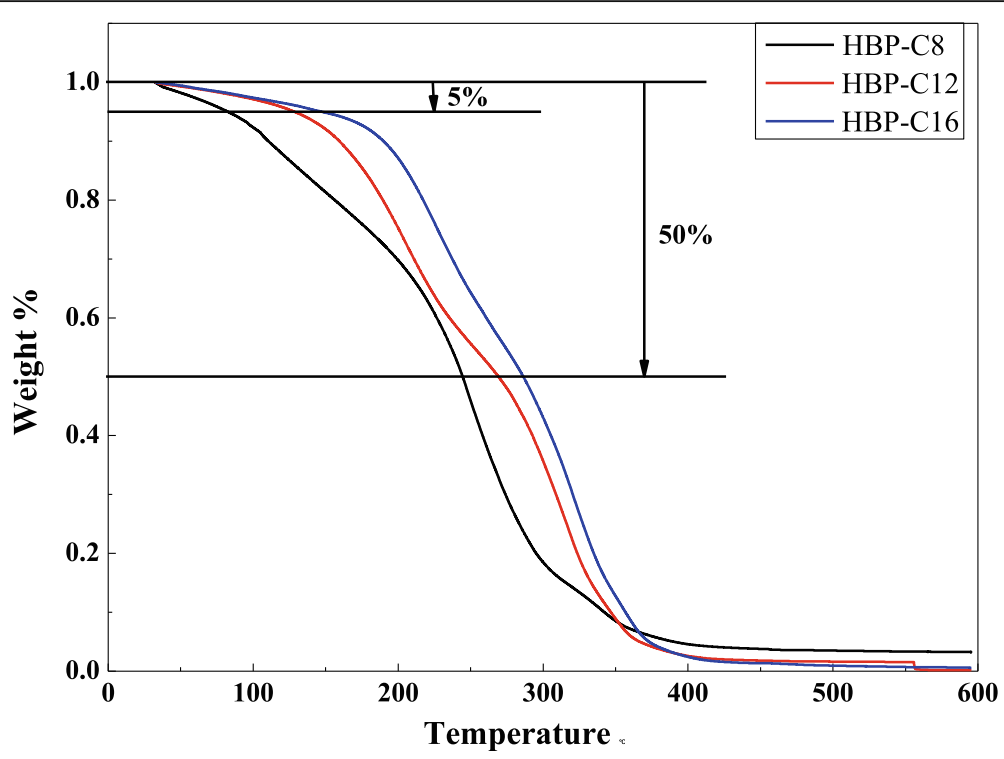

Fig. 6 TGA thermogram of HBP-C

the concentration required to form micelles is correspondingly reduced.

\subsection{CMC of HBP-C}

The ultraviolet absorption spectra of HBP-C8, HBP-C12 and HBP-C16 were shown in Fig. 8. As seen from the figure, when HBP-C was added in $\mathrm{I}_{3}{ }^{-}$solution, the absorption spectrum of $\mathrm{I}_{3}{ }^{-}$solution nearly had no change in $350 \mathrm{~nm}$. The maximum absorption peak changed from $288 \mathrm{~nm}$ to $285.5 \mathrm{~nm}$, which showed the ultraviolet absorption spectrum of $\mathrm{I}_{3}{ }^{-}$solution was slightly impacted by the addition of HBP-C. In addition, when the concentration of HBP-C was different; the absorption peak strength also significantly changed. The ultraviolet absorbance curve under different concentrations was drawn at $285.5 \mathrm{~nm}$ and $350 \mathrm{~nm}$, the result was shown in Fig. 8b, d and f. As shown in Fig. 8b, when the concentration of HBP-C8 increased, the absorbance of solution slightly increased, but only the concentration of HBP-C8 increased to $0.021 \mathrm{~g} \cdot \mathrm{L}^{-1}$, the absorbance of solution had obvious increase. The curve obviously displayed inflection point which was the CMC of HBP-C8.

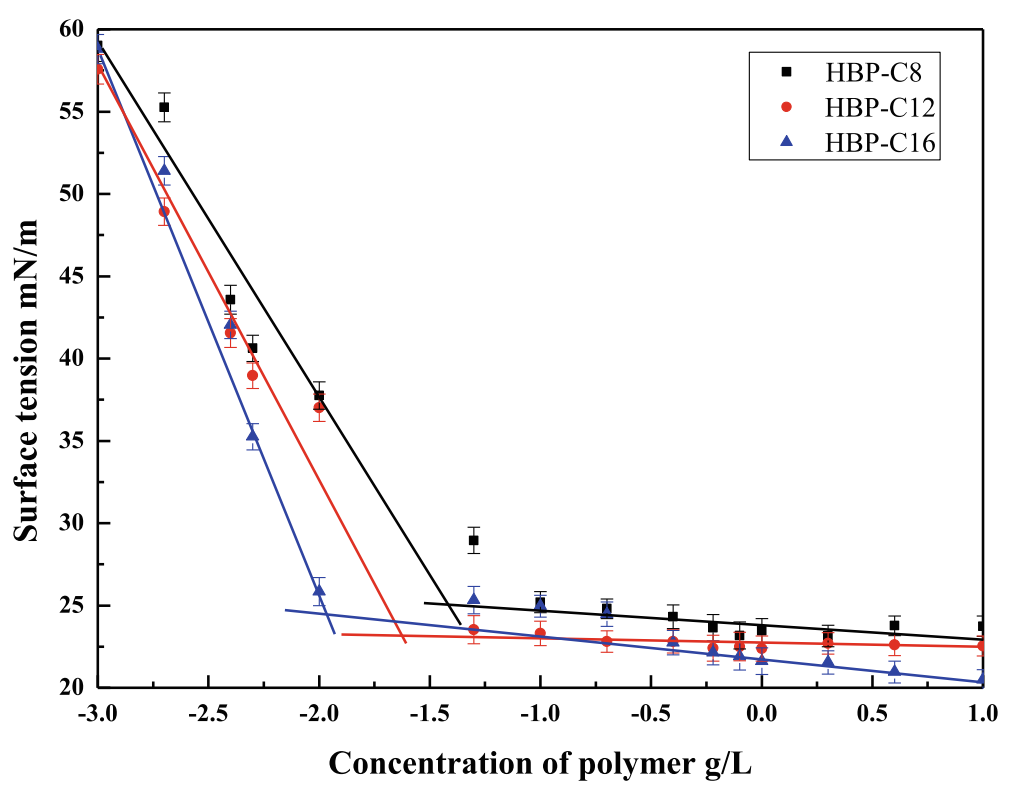

Fig. 7 Surface tension of HBP-C8, HBP-C12, HBP-C16 

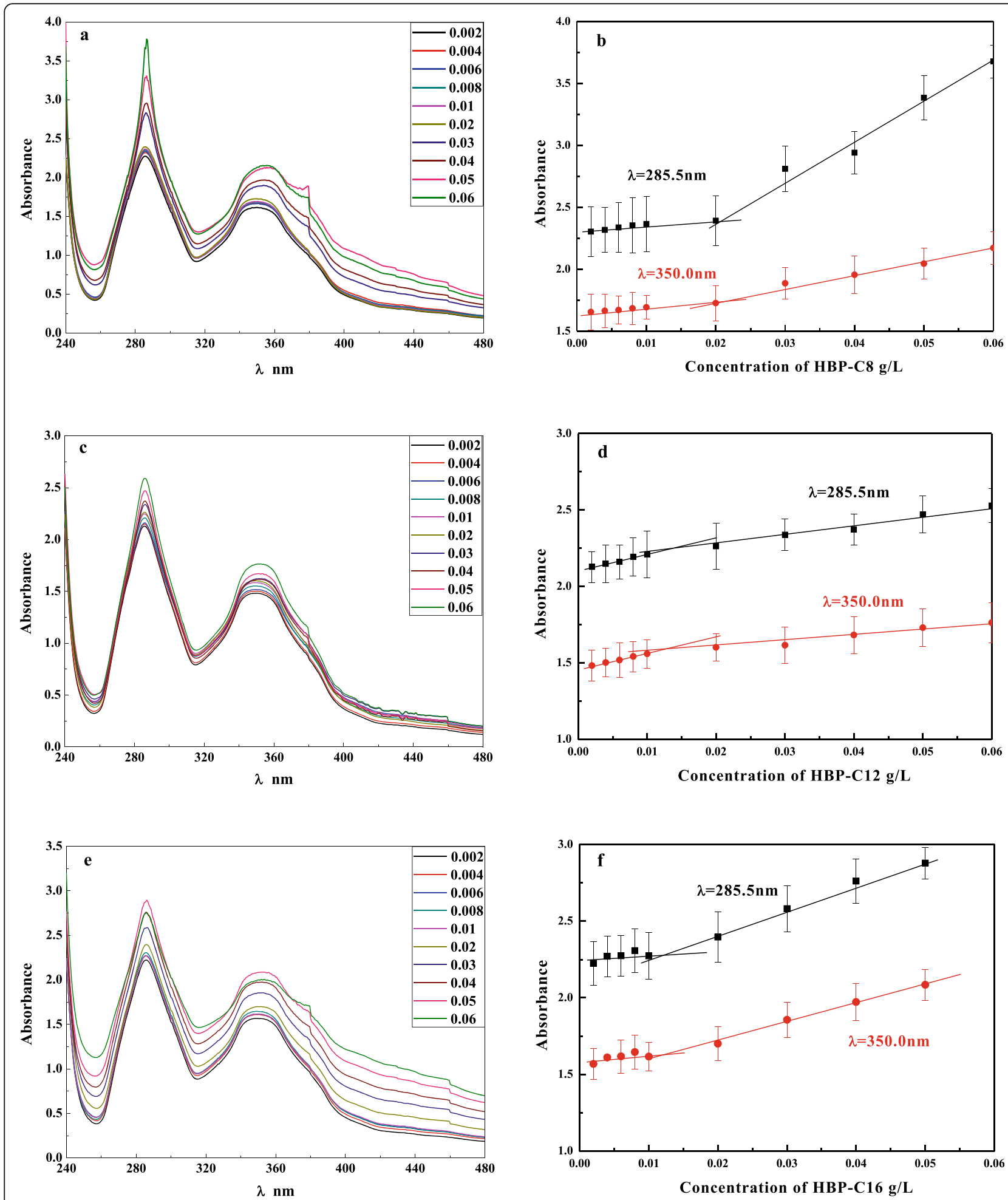

Fig. 8 The ultraviolet absorption spectra of HBP-C8 (a, b), HBP-C12 (c, d) and HBP-C16 (e, $\mathbf{f})$ with different concentrations

CMC of HBP-C12 and HBP-C16 also could be concluded according to above method which respectively were $0.013 \mathrm{~g} \cdot \mathrm{L}^{-1}$ and $0.012 \mathrm{~g} \cdot \mathrm{L}^{-1}$. Comparing the $\mathrm{CMC}$ values obtained from surface tension method and UV spectrophotometry, CMC value measured by UV spectrophotometry was less than that obtained by surface tension method. This is due to HBP-C has spherical hydrophilic core and there are a lot of holes in molecular 
structure, so it can encapsulate $\mathrm{I}_{3}{ }^{-}$at a relatively low concentrations and make the absorbance of solution change. So HBP-C can display single molecular micellar properties, which can package hydrophilic small molecule in relatively low concentration.

\section{Conclusions}

A series of HBP-C was synthesized by grafting modification, and the synthesis conditions were optimized which were the initial reaction temperature was ice water bath, the dosage of pyridine was twice of the mass of HBP. The chemical structure of HBP-C was characterized by FTIR, NMR and GPC. The results showed the reaction between the terminal hydroxyl with chloride was performed as expected. The thermal performance of HBP-C analyzed by DSC and TG was strongly influenced by the length of end alkyl chain. The surface activity of HBP-C analyzed by surface tension method and UV spectrophotometry showed that HBP-C displayed better surface activity, which could effectively reduce the surface tension of water. HBP-C display single molecular micellar properties, which can package hydrophilic small molecule in relatively low concentration and are expected to be used in the encapsulation of dye molecules and other fields. The solution properties of hyperbranched polymer surfactants have been studied, which provides a theoretical basis for further exploration the application of hyperbranched polymer surfactants.

\section{Supplementary Information}

The online version contains supplementary material available at https://doi. org/10.1186/s42825-020-00049-6.

Additional file 1: Fig. S1. The influence of reaction temperature on product grafting rate. Fig. S2. The influence of solvent dosage on product grafting rate.

\section{Acknowledgements \\ This work was funded by the Key Scientifific Research Group of Shaanxi Province (2020TD-009), Key Scientific Research Program of Shaanxi Provincial Education Department (Collaborative Innovation Center Project) (20JY003), Science and Technology Plan Project of Xi'an Weiyang District (No. 201907) and the Youth Innovation Team of Shaanxi Universities.}

\section{Authors' contributions}

RLF and QTT conceived and designed the study. TZ and ZGG performed the experiments and analyzed the experiments data. RLF, QTT, TZ and ZGG reviewed and edited the manuscript. All authors read and approved the manuscript.

\section{Funding}

This work was funded by the Key Scientifific Research Group of Shaanxi Province (2020TD-009), Key Scientific Research Program of Shaanxi Provincial Education Department (Collaborative Innovation Center project) (20JY003), Science and Technology Plan Project of Xi'an Weiyang District (No. 201907) and the Youth Innovation Team of Shaanxi Universities.

\section{Availability of data and materials}

All data and material generated or analyzed during this study are included in this published article. The authors declare that the data in this article is reliable.

\section{Competing interests}

The authors declare that they have no competing interests.

Received: 22 June 2020 Accepted: 22 December 2020

Published online: 15 April 2021

\section{References}

1. Sun ZY. Hyperbranched polymers in modifying natural plant fibers and their applications in polymer matrix composites-a review. J Agric Food Chem. 2019;67:8715-24. https://doi.org/10.1021/acs.jafc.9b03436.

2. Mirshahi F, Bastani S, Sari MG. Studying the effect of hyperbranched polymer modification on the kinetics of curing reactions and physical/ mechanical properties of UV-curable coatings. Prog Org Coat. 2016:90:18799. https://doi.org/10.1016/j.porgcoat.2015.10.015.

3. Demircan D, Zhang BZ. Facile synthesis of novel soluble cellulosegrafted hyperbranched polymers as potential natural antimicrobial materials. Carbohydr Polym. 2017;157:1913-21. https://doi.org/10.1016/j. carbpol.2016.11.076

4. Ma XP, Huang L, Yang L, et al. Synthesis and performance evaluation of cyclodextrin modified hyperbranched polymer. Fine Chem. 2020;37:604-8+ 628. https://doi.org/10.13550/j.jxhg.20190647.

5. Mesias R, Murillo EA. Hyperbranched polyester polyol modified with polylactic acid. J Appl Polym Sci. 2015;132. https://doi.org/10.1002/ app.41589.

6. Luan YG, Zhang XA, Jiang SL, et al. Self-healing supramolecular polymer composites by hydrogen bonding interactions between hyperbranched polymer and graphene oxide. Chin J Polym Sci. 2018;36:584-91. https://doi. org/10.1007/s10118-018-2025-y.

7. Yin Y, Yang LM, Makoto $Y$, et al. Synthesis and gas permeation properties of star-like poly (ethylene oxide) s using hyperbranched polyimide as central core. Polym J. 2004;36:294-302.

8. Saikia A, Hazarika D, Karak N. Tough and biodegradable thermosets derived by blending of renewable resource based hyperbranched epoxy and hyperbranched polyester. Polym Degrad Stab. 2019;159:15-22. https://doi. org/10.1016/j.polymdegradstab.2018.11.012

9. Zamboulis A, Nakiou EA, Christodoulou E, et al. Polyglycerol hyperbranched polyesters: synthesis, properties and pharmaceutical and biomedical applications. Int J Mol Sci. 2019;20. https://doi.org/10.3390/ijms20246210.

10. Gurunathan T, Mohanty S, Nayak SK. Hyperbranched polymers for coating applications: a review. Polym-Plast Technol Eng. 2016;55:92-117. https://doi. org/10.1080/03602559.2015.1021482.

11. Zhang LY, Xue W, Gu LM. Modification of hyperbranched hemicellulose polymer and its application in adsorbing acid dyes. Cellulose. 2019;26:5583601. https://doi.org/10.1007/s10570-019-02483-0.

12. Qiang TT, Hunag ZF, Wang XC. Research progress on hyperbranched polymer surfactant. Leather Sci Eng. 2011;21:30-4. https://doi.org/10.3969/j. issn.1004-7964.2011.06.006

13. Zhang WW, Jiang WW, Zhang DL, et al. Synthesis, characterization and association behavior of linear-dendritic amphiphilic diblock copolymers based on poly (ethylene oxide) and a dendron derived from 2,2' -bis (hydroxymethyl)-propionic acid. Polym Chem. 2015;6:2274-82. https://doi. org/10.1039/c4py01385a

14. Chen K, Zhou XD, Wang XR. Synthesis and application of a hyperbranched polyester quaternary ammonium surfactant. J Surfactant Deterg. 2014;17: 1081-8. https://doi.org/10.1007/s11743-014-1624-z.

15. Chen SY, Luo Y, Su GS, et al. Stability of hyperbranched surfactants emulsion. Fine Chemicals. 2019;36:2052-9. https://doi.org/10.13550/j.jxhg. 20180954.

16. Varaprasad NSS, Ramakrishnan S. Hybrasurfs-a new class of hyperbranched surfactants. Langmuir. 2018;34:11464-72. https://doi.org/10.1021/acs. langmuir.8b02022.

17. Chen SY, Luo Y, Su GS, et al. Preparation and properties of anion-nonionic hyperbranched surfactants for high salinity and temperature reservoirs. J Dispers Sci Technol. 2019. https://doi.org/10.1080/01932691.2019.1645683. 
18. Jiang WF, Zhou YF, Yan DY. Hyperbranched polymer vesicles: from selfassembly, characterization, mechanisms, and properties to applications. Chem Soc Rev. 2015;44:3874-89. https://doi.org/10.1039/c4cs00274a.

19. Shavykin OV, Leermakers FAM, Neelov IM, et al. Self-assembly of lysinebased dendritic surfactants modeled by the self-consistent field approach. Langmuir. 2018;34:1613-26. https://doi.org/10.1021/acs.langmuir.7b03825.

20. Qi MW, Huang W, Xiao GY, et al. Synthesis and self-assembly of hyperbranched polymers. Acta Polymeric Sinica. 2017;2:214-28. https://doi org/10.11777/j.issn1000-3304.2017.16324.

21. Hou ZL, Zhou YF, Yan DY. Self-assembly of hyperbranched polymer micelles. Chin Polymer Bull. 2015;(9):5-20. https://doi.org/10.14028/j.cnki. 1003-3726.2015.09.001

22. Singh D, Chauhan NPS. Amphiphilic hyperbranched polymers. Adv Funct Polym Biomed Appl. 2019:111-28. https://doi.org/10.1016/b978-0-12816349-8.00006-0.

23. Xue YT, Sun J, Xiong S. Synthesis, self-assembly and drug solubilization of hyperbranched block polyethers. J Mol Liq. 2018;249:16-23. https://doi.org/ 10.1016/j.molliq.2017.11.026.

24. Qiang TT, Zhang GG, Wang XC. Synthesis and Modification of Hydroxylterminated Hyperbranched Polymer. China Surfactant Deterg Cosmet. 2012; 42:413-7. https://doi.org/10.13218/j.cnki.csdc.2012.06.006.

25. Liu J, Tang L, Leng XM. The comparison and optimization on determination methods of polyester polyol hydroxyl value. Leather Chem. 2011;28:35-47.

26. Xu M, Tan K, Zhou HJ. Effect of terminal groups on the properties of hyperbranched polymers. J Functi Polym. 2003;16:299-303. https://doi.org/ 10.1007/BF02974893.

27. Zhai X, Peleshanko S, Klimenko NS, et al. Amphiphilic dendritic molecules: hyperbranched polyesters with alkyl-terminated branches. Macromolecules. 2003;36:3101-10. https://doi.org/10.1021/ma021383j.

\section{Publisher's Note}

Springer Nature remains neutral with regard to jurisdictional claims in published maps and institutional affiliations.

\section{Submit your manuscript to a SpringerOpen ${ }^{\circ}$ journal and benefit from:}

- Convenient online submission

- Rigorous peer review

- Open access: articles freely available online

- High visibility within the field

- Retaining the copyright to your article

Submit your next manuscript at $\boldsymbol{\nabla}$ springeropen.com 